\title{
Risk factors for short- and long-term complications after groin surgery in vulvar cancer
}

\section{F Hinten*,', LCG van den Einden', JCM Hendriks², AGJ van der Zee ${ }^{3}$, J Bulten ${ }^{4}$, LFAG Massuger', HP van de Nieuwenhof' and JA de Hullu'}

'Department of Obstetrics and Gynaecology, Radboud University Nijmegen Medical Centre, PO Box 9101, 6500 HB Nijmegen, The Netherlands; ${ }^{2}$ Department of Statistics, Radboud University Nijmegen Medical Centre, Nijmegen, The Netherlands; ${ }^{3}$ Department of Obstetrics and Gynaecology, University Medical Centre Groningen, Groningen, The Netherlands; ${ }^{4}$ Department of Pathology, Radboud University Nijmegen Medical Centre, Nijmegen, The Netherlands

\begin{abstract}
BACKGROUND: The cornerstone of treatment in early-stage squamous cell carcinoma (SCC) of the vulva is surgery, predominantly consisting of wide local excision with elective uni- or bi-lateral inguinofemoral lymphadenectomy. This strategy is associated with a good prognosis, but also with impressive treatment-related morbidity. The aim of this study was to determine risk factors for the short-term (wound breakdown, infection and lymphocele) and long-term (lymphoedema and cellulitis/erysipelas) complications after groin surgery as part of the treatment of vulvar SCC.

METHODS: Between January 1988 and June 2009, 164 consecutive patients underwent an inguinofemoral lymphadenectomy as part of their surgical treatment for vulvar SCC at the Department of Gynaecologic Oncology at the Radboud University Nijmegen Medical Centre. The clinical and histopathological data were retrospectively analysed.

RESULTS: Multivariate analysis showed that older age, diabetes, 'en bloc' surgery and higher drain production on the last day of drain in situ gave a higher risk of developing short-term complications. Younger age and lymphocele gave higher risk of developing longterm complications. Higher number of lymph nodes dissected seems to protect against developing any long-term complications. CONCLUSION: Our analysis shows that patient characteristics, extension of surgery and postoperative management influence short- and/or long-term complications after inguinofemoral lymphadenectomy in vulvar SCC patients. Further research of postoperative management is necessary to analyse possibilities to decrease the complication rate of inguinofemoral lymphadenectomy; although the sentinel lymph node procedure appears to be a promising technique, in $\sim 50 \%$ of the patients an inguinofemoral lymphadenectomy is still indicated.
\end{abstract}

British Journal of Cancer (201 I) 105, 1279-1287. doi:10.1038/bjc.201 I.407 www.bjcancer.com

Published online 4 October 201 I

(c) 201 I Cancer Research UK

Keywords: vulvar cancer; postoperative complications; morbidity; surgery

Vulvar squamous cell carcinoma (SCC) is a rare disease and accounts for $\sim 3-5 \%$ of all female genital malignancies (Hacker, 2005). The incidence is $\sim 1-2$ per 100000 (van de Nieuwenhof et al, 2009). The majority of the patients with vulvar SCC have early-stage disease: a cT1 $(<2 \mathrm{~cm})$ or cT2 $(>2 \mathrm{~cm})$ tumour without suspicious inguinal lymph nodes. The standard treatment of early-stage SCC of the vulva consists of wide local excision (WLE) of the tumour combined with an inguinofemoral lymphadenectomy (removal of all superficial lymph nodes and the medial femoral lymph nodes) (Levenback et al, 1996; de Hullu et al, 2004). The inguinofemoral lymphadenectomy has significant short- and long-term complications, which are a major concern for both patients and clinicians. Wound breakdown, wound infection, formation of lymphoceles, development of lymphoedema and cellulitis/erysipelas are the most documented complications,

*Correspondence: Dr F Hinten; E-mail: F.Hinten@obgyn.umcn.nl Received 31 May 2011; revised 12 September 2011; accepted 13 September 201 I; published online 4 October $201 \mathrm{I}$ occurring in up to $85 \%$ of the patients (Podratz et al, 1983; Gaarenstroom et al, 2003).

Only 25-35\% of patients with early-stage disease will have lymph node metastases (Hacker et al, 1981; Burger et al, 1995; Bell et al, 2000; Katz et al, 2003). There are no noninvasive techniques such as palpation, ultrasound, CT, PET and MRI available with a high enough negative predictive value to safely omit inguinofemoral lymphadenectomy in a selection of patients (Oonk et al, 2006). This urged the introduction of the sentinel lymph node (SLN) procedure in vulvar SCC. After excellent results in different accuracy studies (Ansink et al, 1999; De Cicco et al, 2000; de Hullu et al, 2000; Levenback et al, 2001; Sliutz et al, 2002; Moore et al, 2003), van der Zee et al (2008) showed in the 'Groningen International Study on Sentinel nodes in Vulvar cancer I' (GROINSS-V I) with the combined technique that in early-stage vulvar SCC patients with a negative SLN, the groin recurrence rate is low, survival is excellent and the treatment-related morbidity is minimal.

Despite the excellent outcomes of the SLN procedure, only patients with small $(<4 \mathrm{~cm})$ unifocal tumours are eligible for this technique. Therefore, in $\sim 50 \%$ of the patients, there is still an 
indication for inguinofemoral lymphadenectomy. The modifications of the past decades have been introduced to decrease morbidity without compromising prognosis. 'En bloc' surgery has been replaced by the triple incision technique (de Hullu et al, 2002). Performing a superficial lymphadenectomy alone gives a decrease in survival (Stehman et al, 1992a; Burke et al, 1995), and hence at least the lymph nodes medial of the femoral vessels should be removed. In the literature, sparing of the saphenous vein does not reduce lymphoedema in all studies (Podratz et al, 1983; Zhang et al, 2000; Rouzier et al, 2003). Sartorius transposition did not decrease the morbidity (Rouzier et al, 2003; Judson et al, 2004).

The direct postoperative management for patients with vulvar SCC has not been described extensively. Gould et al (2001) showed that prophylactic antibiotics and duration of drains in situ were no predictors for the development of wound infection and late complications (lymphoedema and cellulitis). The drains were removed when the output was $<30 \mathrm{ml}$ per day. Gaarenstroom et al (2003) described that the drains were removed when the fluid production was $<50 \mathrm{ml}$ per day after at least 5 days. However, the reason for this specific duration was not based on study results. In breast cancer, the postoperative management after axillary lymphadenectomy has been studied in more detail. There is no clear evidence that the use of a drain after axillary surgery reduces the incidence of lymphocele formation (Zavotsky et al, 1998; Talbot and Magarey, 2002; Soon et al, 2005). The studies in breast cancer that compared early with late drain removal (Inwang et al, 1991; Gupta et al, 2001; Dalberg et al, 2004) concluded that early drain removal was safe, but that the incidence of lymphoceles was higher in this group.

The aim of this study is to investigate the influence of patients' characteristics, extension of surgery and postoperative management on the short- and long-term complication rate after inguinofemoral lymphadenectomy in patients with SCC of the vulva.

\section{PATIENTS AND METHODS}

\section{Patients}

Data of 283 consecutive patients with vulvar SCC who were treated at the Department of Gynaecologic Oncology at the Radboud University Nijmegen Medical Centre (RUNMC) between 1 January 1988 and 30 June 2009 were retrieved from medical files. A total of 78 patients were excluded from the current analysis because their groins were not treated surgically $(n=8)$, the primary treatment took place in another medical centre $(n=21)$, no groin surgery was performed at primary treatment $(n=36)$, only superficial inguinal lymphadenectomy was performed $(n=4)$ only debulking of lymph node metastases was performed $(n=2)$ or posterior exenteration was performed $(n=3)$. Four patients were excluded because their medical files could not be retrieved. In 205 patients groin surgery was performed; 41 patients only underwent SLN procedure and were excluded. In 2001, the SLN procedure (unilateral or bilateral) was introduced in the RUNMC initially in an accuracy study (followed by lymphadenectomy) that preceded the GROINSS V-studies by van der Zee et al (2008). Data of 164 patients were available for further analysis in this study. Local surgery consisted of a WLE or radical vulvectomy. From 1988 to 1993, standard local treatment consisted of a radical vulvectomy. After 1993, the WLE was introduced; it was carried out when the tumour was clinically resectable with a macroscopically measured normal tissue margin of $1-2 \mathrm{~cm}$ despite the tumour diameter. After the introduction of the WLE, radical vulvectomy was only considered in patients with multifocal tumours and in case of an abnormal remainder of the vulva with complaints. Groin surgery consisted of 'en bloc' inguinofemoral lymphadenectomy from 1988 to 1993. In 1993, the triple incision technique was introduced (de Hullu et al, 2002): when the medial margin of the tumour was $>1 \mathrm{~cm}$ from the midline, unilateral or otherwise a bilateral inguinofemoral lymphadenectomy was performed. A total of $62 \%$ of our patients underwent inguinofemoral lymphadenectomy through triple incision technique after 1993 vs 17\% before 1993. It took some time until the triple incision technique was fully integrated in our Gynaecologic Oncology centre. The inguinofemoral lymphadenectomy contained resection of superficial lymph nodes as well as deep femoral nodes. For the resection of inguinal lymph nodes, the fatty tissue beneath the subcutaneous tissue down to the fascia lata was removed. The saphenous vein was spared when possible. After splitting the fascia lata, the fatty tissue medial to the femoral vessels within the opening of the fossa ovalis was resected to perform femoral lymphadenectomy. The lateral part of the fascia lata was spared and no sartorius transposition was performed.

\section{Data}

All data were retrospectively collected from a database and the patient charts. Parameters extracted were: patients' characteristics (age, diabetes, peripheral vascular disease, body mass index (BMI) and continuation of antibiotics), type of surgery ('en bloc' approach or triple incision technique, unilateral or bilateral inguinofemoral lymphadenectomy, the ligation of the saphenous vein, number of removed lymph nodes, presence or absence of lymph node metastases and adjuvant radiotherapy) and postoperative management (drain management). In the RUNMC, all patients received standard antibiotics during surgery: Cefazoline $1000 \mathrm{mg}$ and Metronidazol $500 \mathrm{mg}$; in some individual patients, the treatment with antibiotics extended for some additional days. 'Antibiotics' in our study was defined as the continuation of antibiotics after surgery. Patients who underwent an inguinofemoral lymphadenectomy received high-vacuum Redon drains ( $775 \mathrm{~mm} \mathrm{Hg}$ (0.9 bar) negative pressure) in the groins postoperatively. In general, the drains were in situ for 5 days and these were removed when the production was decreasing and under $50-$ $100 \mathrm{ml}$ per day. 'Duration of the drains in the groins' was defined as the time between operation and the day the drains were removed. The 'fluid production' was measured per day. Prescription of elastic stockings was a standard procedure in patients who underwent inguinofemoral lymphadenectomy. 'Hospitalisation time' was defined as the day of operation (day 0 ) and the number of postoperative days in the hospital. The influence of adjuvant radiotherapy was only assessed for the long-term complications.

Definitions and the frequencies of the short- and long-term complications after inguinofemoral lymphadenectomy are shown in Table 1. In total, 137 patients (84\%) suffered from a complication of any kind after inguinofemoral lymphadenectomy. We also assessed the frequency of any of the short-term complications and any of the long-term complications. Standard follow-up was every 3 months in the first 2 years; from the third to the fifth year, it was twice a year and yearly thereafter.

\section{Statistical methods}

All events were described per groin, but analysis of complication rate per groin might overrate the influence of patient characteristics, because these were doubled in case of a bilateral lymphadenectomy. In patients who underwent bilateral lymphadenectomy, we randomly analysed the right or the left groin in order to minimise bias. We started at the top of the database and took the right groin in the first patient and the left groin in the second and so on without knowing in which groin the complications occurred.

Variables eligible for entry were analysed using SPSS software (version 16.0.01 for Windows, SPSS, Chicago, IL, USA). Univariate logistic regression was used to assess the risk of patients' 
Table I Overview of short- and long-term complications of the groin after inguinofemoral lymphadenectomy $(N=164)$

\begin{tabular}{|c|c|c|}
\hline & $n / N(\%)$ & \\
\hline \multicolumn{3}{|l|}{ Short term ( $<4$ weeks) } \\
\hline Wound breakdown & $30 / 160(18.8)$ & Disrupted groin wound(s) $>2 \mathrm{~cm}$ \\
\hline Wound infection & $46 / 161(28.6)$ & Purulent exudates and/or positive culture and erythema, oedema and localised pain \\
\hline Lymphocele & $47 / 161(29.2)$ & Clinically obvious and/or confirmed by puncture or ultrasound scan \\
\hline Any short-term complication & $94 / 161(57.3)$ & One or more of the three short-term complications \\
\hline \multicolumn{3}{|l|}{ Long term (>4 weeks) } \\
\hline Lymphoedema & $78 / 160(48.8)$ & Elastic bandages or other forms of lymph drainage were required \\
\hline Cellulitis/erysipelas & $54 / 160(33.8)$ & Erythematous and scalding skin with/without positive culture for Streptococcus and $\mathrm{T}>39^{\circ} \mathrm{C}$ \\
\hline Any long-term complication & $102 / 160(63.8)$ & One or more of the two long-term complications \\
\hline
\end{tabular}

Abbreviations: $N=$ patients with valid observation; $n=$ number of patients with a complication.

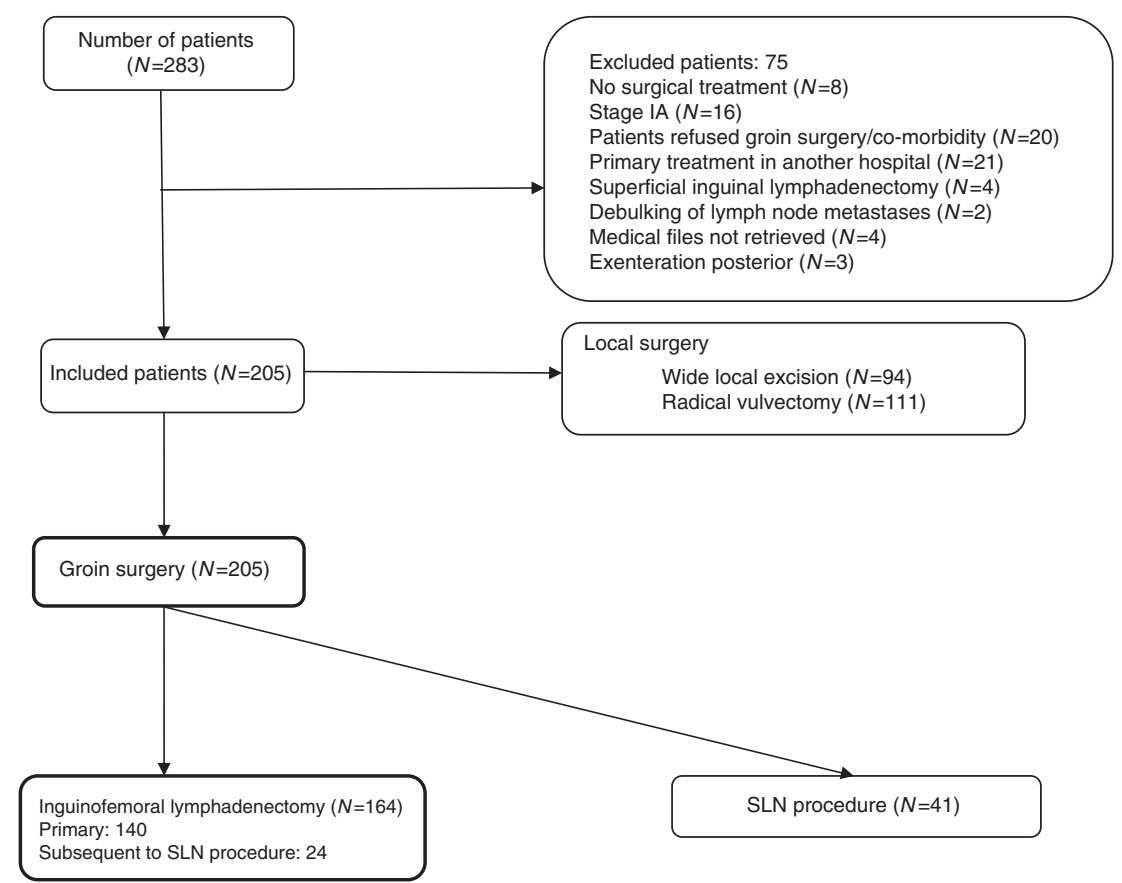

Figure I Inclusion chart.

characteristics, type of surgery and postoperative management on the short-term complications and long-term complications, respectively any of the short-term complications and the longterm complications as the single type complications. The odds ratios with the $95 \%$ confidence interval (CI) are presented. Multivariate logistic regression with forward selection procedure was used to identify those variables that independently contributed to the risk of short-term complications and long-term complications (statistically significant variables from univariate logistic regression). After entry the adjusted odds ratios with $95 \%$ CI of the final model are presented. A $P$-value of $<0.05$ was considered statistically significant.

An IRB approval was not necessary for this retrospective study.

\section{RESULTS}

Of all patients who underwent inguinofemoral lymphadenectomy for primary SCC of the vulva $(n=164), 140$ patients underwent primary inguinofemoral lymphadenectomy, whereas 24 patients underwent inguinofemoral lymphadenectomy subsequent to SLN procedure during the learning curve (with standard inguinofemoral lymphadenectomy after SLN procedure) or because of positive SLN(s) in GROINSS-V I (van der Zee et al, 2008). In 301 groins of 164 patients, an inguinofemoral lymphadenectomy was performed (27 patients only unilateral), of which 73 patients underwent surgery through the 'en bloc' approach. Figure 1 shows a flowchart of patients with SCC who underwent groin surgery. Table 2 shows the features of the research population.

The SLN procedure was not yet introduced in our department before 2001 . In retrospect, $\sim 50 \%$ of the patients in our study population were not or would not have been eligible for a SLN procedure because the tumour was $>4 \mathrm{~cm}$ and/or multifocal. The details of use (duration and results) of the stockings were not well documented in the medical charts, and hence this item was excluded from the analysis.

Risk factors for short-term complications and long-term complications were assessed with univariate analysis (Tables 3 and 4).

Using multivariate analysis, 'en bloc' surgery (odds ratio 2.72, 95\% CI 1.16-6.37) and older age (odds ratio 1.06, 95\% CI 1.02 1.10) were both independent risk factors for developing wound breakdown. 'En bloc' surgery (odds 2.66, 95\% CI 1.15-6.15) and higher drain production on the last day the drain was in situ 
Table 2 Features of the research population with median values and percentages

\begin{tabular}{|c|c|c|c|}
\hline Variables & $\mathbf{N}$ & Median (range) & n (\%) \\
\hline \multicolumn{4}{|l|}{ Patient characteristics } \\
\hline Age (years) & 164 & $7 \mid(3 \mid-92)$ & - \\
\hline Diabetes & 164 & - & $19(11.6)$ \\
\hline Peripheral vascular disease & 164 & - & $8(4.9)$ \\
\hline $\mathrm{BMI}\left(\mathrm{kg} \mathrm{m}^{-2}\right)$ & 155 & $26.6(17.6-48.4)$ & - \\
\hline Continuation of antibiotics & 162 & - & $99(61.1)$ \\
\hline \multicolumn{4}{|l|}{ Surgical technique } \\
\hline Bilateral IFL & 164 & - & $137(83.5)$ \\
\hline En bloc & 164 & - & $73(44.5)$ \\
\hline Ligation saphenous vein & 160 & - & $32(20.0)$ \\
\hline Total nodes dissected (no. of nodes) & 164 & $9(0-25)$ & - \\
\hline Total positive nodes (no. of nodes) & 164 & $0(0-7)$ & - \\
\hline Extracapsular growth (no. of nodes) & 164 & $0(0-7)$ & - \\
\hline \multicolumn{4}{|l|}{ Postoperative management } \\
\hline Duration drain (days) & 149 & $8(0-27)$ & - \\
\hline Drain production last day (ml) & 122 & $40.0(0-860)$ & - \\
\hline Total drain production (ml) & 145 & $630(20-7540)$ & - \\
\hline Adjuvant radiotherapy & 163 & - & $40(24.5)$ \\
\hline Hospital stay (days) & 164 & $15(4-60)$ & - \\
\hline Follow-up (months) & 164 & $50.3(0.1-215)$ & - \\
\hline FIGO stage (new) & 164 & - & \\
\hline IB & & & $78(47.6)$ \\
\hline$\|$ & & & $8(4.9)$ \\
\hline$\| \mathrm{AA}$ & & & $24(14.6)$ \\
\hline$\| \mathrm{IIB}$ & & & II (6.7) \\
\hline IIIC & & & $29(17.7)$ \\
\hline$\| \mathrm{A} / \mathrm{B}$ & & & $9(5.5)$ \\
\hline IVA & & & $4(2.4)$ \\
\hline IVB & & & I (0.6) \\
\hline
\end{tabular}

Abbreviations: $\mathrm{BMI}=$ body mass index; $\mathrm{FIGO}=$ International Federation of Gynaecology and Obstetrics; $N=$ number of patients with valid observation; $n=$ number of patients with specific feature; IFL = inguinofemoral lymphadenectomy; - = not applicable.

(odds ratio 1.05, 95\% CI 1.00-1.09) were the only independent risk factors for wound infection. Higher drain production on the last day the drain was in situ (odds ratio 1.05, 95\% CI 1.01-1.10) was a risk factor for developing lymphocele. Diabetes (odds ratio 4.10, 95\% CI 1.04-16.05) and higher drain production on the last day the drain was in situ (odds ratio 1.11, 95\% CI 1.04-1.19) were risk factors for developing any of the short-term complications. Younger age was the only independent risk factor for developing lymphoedema (odds ratio $0.95,95 \%$ CI $0.93-0.98$ ). The independent risk factors for cellulitis/erysipelas were younger age (odds ratio $0.96,95 \%$ CI $0.93-0.98$ ) and lymphocele (odds ratio 3.28 , $95 \%$ CI 1.50-7.19). Higher number of lymph nodes dissected seems to protect against developing any long-term complications (odds ratio $0.92,95 \%$ CI $0.84-1.00$ ) and younger age was a risk factor (odds ratio $0.94,95 \%$ CI $0.92-0.97$; Table 5).

\section{DISCUSSION}

In this study we found different risk factors for the short- and long-term complications after inguinofemoral lymphadenectomy as part of the standard treatment for primary vulvar SCC. Older age, diabetes, 'en bloc' surgery and higher drain production on the last day the drain was in situ were significant risk factors for shortterm complications. Younger age and lymphocele gave higher risk of developing long-term complications.

We found that older age was associated with higher risk for wound breakdown. This can be explained by the deterioration of wound healing with age. On the other hand, younger age was correlated with the long-term complications lymphoedema and cellulitis/erysipelas. One should realise that younger women are more active and might be more limited in their daily activities by possible lymphoedema; older people may experience more restrictions from other diseases, such as cardiac problems resulting in lymphoedema. Our study showed that diabetes was associated with wound breakdown and any short-term complication. It is well known that diabetes mellitus is associated with wound healing problems in many surgical disciplines (Trussell et al, 2008; Chen et al, 2009; McConnell et al, 2009; Ogihara et al, 2009). Therefore, the glucose levels in patients with diabetes should be regulated strictly to diminish the influence of diabetes on the short-term complications.

In our study the 'en bloc' approach was the only surgical technique-related risk factor found. In 1993, the triple incision technique was introduced in the RUNMC. In our study we found a decrease in complication rate after 1993, especially in the shortterm complication rate (76.2\% before 1993 and $55.7 \%$ after 1993). We did expect to find this result, as our study showed, as expected in literature (Hacker et al, 1981; Podratz et al, 1983; Lin et al, 1992), the 'en bloc' approach to be a risk factor for both wound breakdown and wound infection. This can also be explained by the higher rate of triple incisions performed after 1993 compared with before 1993 (61.7\% vs 17.4\%). Nowadays, 'en bloc' surgery is only performed in patients with large suspicious inguinofemoral lymph nodes to prevent skin bridge and groin recurrences. We hypothesised that a higher total amount of dissected lymph nodes during surgery would impose a risk for lymphoedema, which was based on the idea that less lymph nodes may drain less lymph fluid. The mean number of nodes dissected in our study was 9.45 nodes per groin, and a higher amount of nodes dissected as a risk factor for lymphoedema was not confirmed in this study. On the contrary, a higher amount seemed to protect against developing any long-term complications. Besides, only in cellulitis/erysipelas a cutoff point was recognised, namely $10 \mathrm{lymph}$ nodes $(>10$ lymph nodes dissected posed protection). We did not have an explanation for this finding. Courtney-Brooks et al (2010) showed that removal of $>10$ lymph nodes might be associated with better survival in FIGO stage III patients. The prognostic impact of the number of lymph nodes dissected remains unclear. It is advised to remove between 6 and 8 lymph nodes per groin (Butler et al, 2010; Woelber et al, 2011), but variations in anatomy and other factors make node counting an unreliable measure of surgical quality (Stehman et al, 2009).

In melanoma of the lower extremities, patients also undergo lymphadenectomy, in most cases combined with pelvic lymphadenectomy. There are comparable complication rates described as in vulvar cancer patients: wound breakdown 3-26\%, wound infection 9-30\%, lymphocele 5-46\% and lymphoedema $20-64 \%$ (Baas et al, 1992; Beitsch and Balch, 1992; Karakousis and Driscoll, 1994; Lawton et al, 2002; Serpell et al, 2003; de Vries et al, 2006). Apparently, morbidity after inguinofemoral lymphadenectomy is impressive despite the type of the primary tumour.

The use of drains after inguinofemoral lymphadenectomy is generally accepted worldwide and therefore used in our gynaecologic oncology department. There are no standardised protocols for the duration of drainage, but in most cases the drains are left in situ for at least 5 days; the postoperative management at the RUNMC is to remove the drains when the production has decreased under $50-100 \mathrm{ml}$ per day. Only two retrospective studies on postoperative management in vulvar SCC report a postoperative protocol on drain management; either remove the drain when the output was $<30 \mathrm{ml}$ per day or when the fluid production was $<50 \mathrm{ml}$ per day after at least 5 days (Gould et al, 2001; Gaarenstroom et al, 2003). Both studies showed, in accordance with our results, that duration of the drain in situ had no influence on the short- and long-term complications after 
Table 3 Odds ratios with 95\% confidence interval of patient characteristics, surgery and postoperative management variables for short-term complications using univariate logistic regression

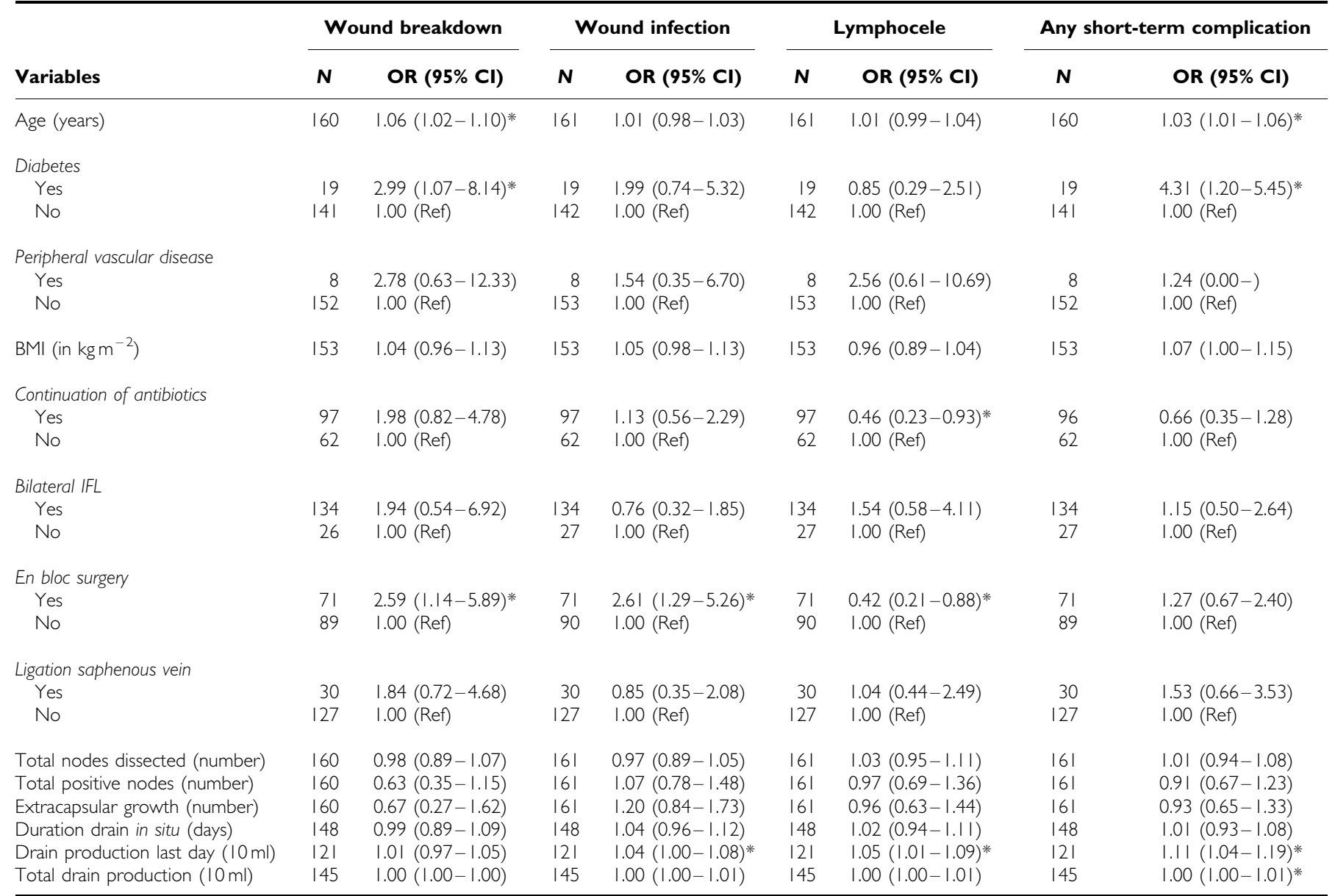

Abbreviations: $\mathrm{N}=$ patients with valid observation; $\mathrm{OR}=$ odds ratio; $\mathrm{Cl}=$ confidence interval; $\mathrm{IFL}=$ inguinofemoral lymphadenectomy; $(10 \mathrm{ml})=$ odds ratio assessed per $\mathrm{I} 0 \mathrm{ml}$ increase of lymph fluid; Ref = reference; $B M I=$ body mass index. $* P<0.05$.

inguinofemoral lymphadenectomy. There is limited literature on drain management in patients after inguinofemoral lymphadenectomy for vulvar SCC, probably because of the low incidence of vulvar SCC and/or the focus on improving quality of life by the SLN procedure.

In contrast with the groin, drain management in the axilla after breast cancer treatment has been extensively studied; most surgeons remove the drain when the drainage volume is $<20-$ $50 \mathrm{ml}$ in the preceding $24 \mathrm{~h}$ and this may take up to 10 days (Tadych and Donegan, 1987; Yii et al, 1995; Bundred et al, 1998; Kopelman et al, 1999; Woodworth et al, 2000). Barwell et al (1997) showed that patients who developed a lymphocele after breast cancer surgery had a higher mean total drain volume $(480 \mathrm{ml})$ than patients who did not develop a lymphocele $(240 \mathrm{ml})$. We found that the total volume of fluid drained from the groin was $\sim 1.5$ times higher, without a significant difference between the patients who did and did not develop a lymphocele. An explanation may be that the lymph nodes of the groin have to drain more lymph fluid from the lower extremities than the lymph nodes in the axilla from the upper extremities.

Our study showed that a higher drain production on the last day that the drain was in situ was associated with an increased risk for lymphocele formation. An explanation for this result is that after removal of the drain, stasis of lymph fluid takes place, which gives rise to lymphoceles. Our study is limited by a small group of patients with known drain production on the last day. These results confirm our hypothesis that more the fluid drained on the last day, the higher the incidence of lymphoceles would be as shown in the studies on breast cancer. In the literature on breast cancer surgery, the amount of postoperative fluid drainage has been found to be significantly influenced by the degree of negative pressure in the drain. The hypothesis is that a high negative suction pressure in the drain may prevent the leaking lymphatics and blood vessels from sealing off, thus leading to prolonged drainage (van Heurn and Brink, 1995; Kopelman et al, 1999; O'Hea et al, 1999; Chintamani et al, 2005). In vulvar SCC, high-vacuum drains are used, but none of the studies defined the amount of negative pressure applied in the drains. There is one prospective study that compared two types of drains, the Blake and the Jackson-Pratt drain. This study showed an increased incidence of overall complication rate associated with the Blake drain (Carlson et al, 2008). These findings show that there is a need for further studies to investigate drain management after inguinofemoral lymphadenectomy.

Compared with a full lymphadenectomy, the SLN procedure has been shown to significantly reduce postoperative morbidity in the GROINSS-V I study (van der Zee et al, 2008). Our data revealed a number of patients who are not eligible for the SLN procedure because of the size of the tumour or multifocality. These patients would still require an inguinofemoral lymphadenectomy with the associated morbidity. Despite the application of the SLN procedure, the complication rate remains high compared with 
Table 4 Odds ratios with 95\% confidence interval of patient characteristics, surgery and postoperative management variables for long-term complications using univariate logistic regression

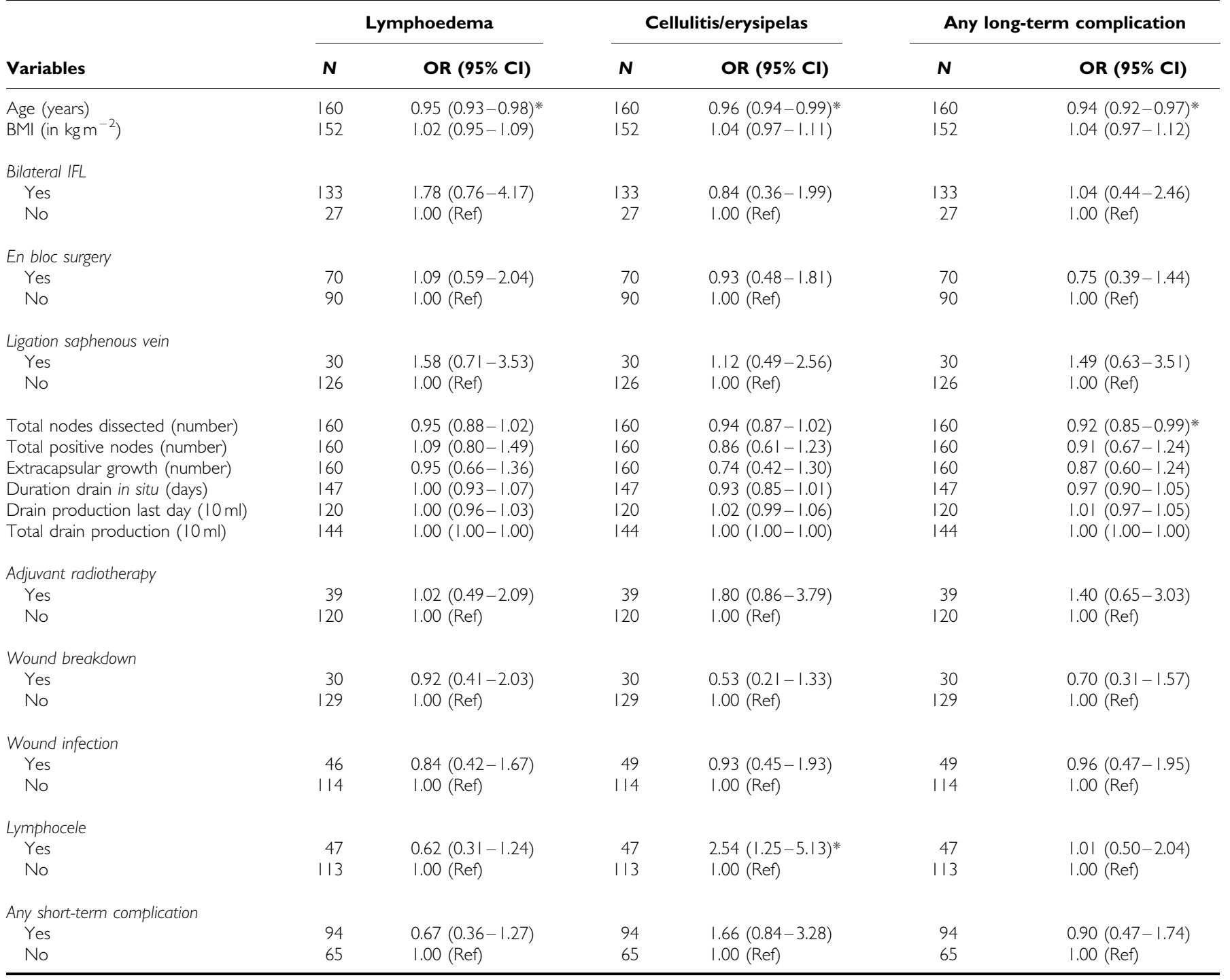

Abbreviations: $N=$ patients with valid observation; $\mathrm{OR}=$ odds ratio; $\mathrm{Cl}=$ confidence interval; $\mathrm{BMI}=$ body mass index; $\mathrm{IFL}=$ inguinofemoral lymphadenectomy; $(\mathrm{I} 0 \mathrm{ml})=$ odds ratio assessed per $10 \mathrm{ml}$ increase of lymph fluid; Ref $=$ reference. $* P<0.05$.

the rates described in the literature (Table 6). This may be explained by the different definitions for complications used in the literature. Apparently, it is difficult to prevent short- and long-term complications other than omitting lymphadenectomy. In the past years, different methods such as ligation of VSM (Podratz et al, 1983; Zhang et al, 2000; Rouzier et al, 2003), sartorius muscle transposition (Rouzier et al, 2003; Judson et al, 2004) and sealing with VH fibrin sealant (Carlson et al, 2008) have been adopted with the attempt to decrease the complication rate, but none of these methods decreased the complication rate after inguinofemoral lymphadenectomy. Hopefully, GROINSS-V II will show that radiotherapy is an attractive and safe alternative for inguinofemoral lymphadenectomy in a substantial number of patients with a positive SLN. A few other treatment options have been described in the literature on vulvar cancer. Primary radiotherapy could be able to replace inguinofemoral lymphadenectomy in patients without suspicious groins. Three studies showed that primary radiotherapy to the groin results in less morbidity but also in a higher number of groin recurrences compared with surgery (Stehman et al, 1992b; Manavi et al, 1997;
Perez et al, 1998). It has been suggested to remove only the bulky lymph nodes before radiotherapy. A study by Hyde et al (2007) showed that the survival is not compromised by only resecting the bulky nodes; however, because of the small study group retrospective nature of the study, a randomised prospective study is recommended. Primary neoadjuvant chemoradiation may be an option in patients with nonresectable tumours to reduce tumour volume, achieve resectability and reduce the extent of surgery. However operability was achieved in $63-92 \%$ of cases, surgical interventions after chemoradiation are associated with high postoperative morbidity (van Doorn et al, 2006). Chemotherapy as a single treatment modality is not common. The data available for any of the applied chemotherapeutic regimens are not sufficient to recommend routine application (Wagenaar et al, 2001; Cormio et al, 2009; Witteveen et al, 2009). Only primary radiotherapy decreases the postoperative morbidity, but with compromising the prognosis. We should keep in mind that a groin recurrence is nearly always fatal. Hence, we recommend treating all patients with vulvar cancer optimally; WLE and groin surgery unless patients are unfit to undergo surgery. Furthermore, research 
Table 5 Adjusted odds ratio with 95\% confidence interval of patient characteristics, surgery and postoperative management variables for short- and longterm complications using multivariate logistic regression with selection procedure

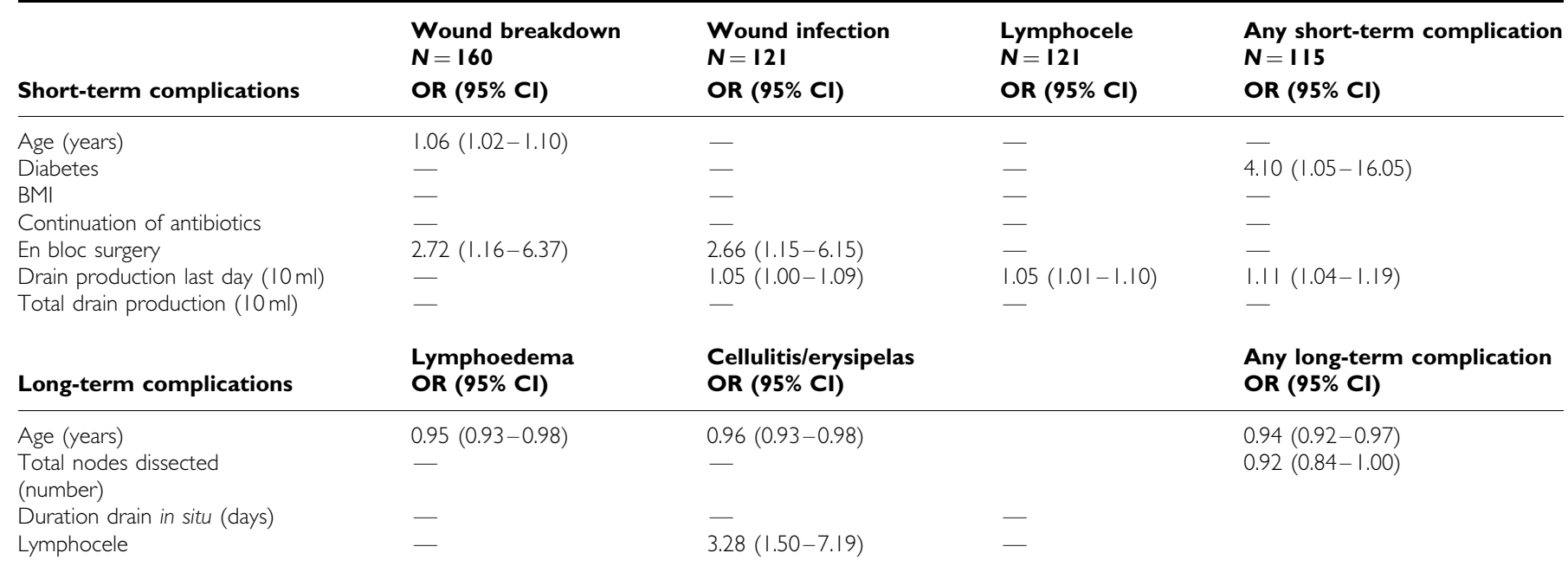

Abbreviations: $\mathrm{N}=$ patients with valid observation; $\mathrm{Cl}=$ confidence interval; $\mathrm{OR}=$ odds ratio; $\mathrm{BMI}=$ body mass index; $-=$ not selected; $(\mathrm{I} 0 \mathrm{ml})=$ odds ratio assessed per $\mathrm{I} 0 \mathrm{ml}$ increase of lymph fluid.

Table 6 Literature overview of short- and long-term complication rate (\%) in patients with vulvar SCC who underwent inguinofemoral lymphadenectomy

\begin{tabular}{|c|c|c|c|c|c|c|c|c|c|}
\hline Author & Year & $N$ & Incision & $\begin{array}{l}\text { After } \\
\text { SLN }\end{array}$ & $\begin{array}{l}\text { Wound } \\
\text { breakdown }\end{array}$ & $\begin{array}{l}\text { Wound } \\
\text { infection }\end{array}$ & Lymphocele & Lymphoedema & $\begin{array}{l}\text { Cellulitis/ } \\
\text { erysipelas }\end{array}$ \\
\hline Podratz et al & 1983 & 175 & 'En bloc' & No & $\begin{array}{l}85 \text { (with infection, } \\
\text { necrosis) }\end{array}$ & $\begin{array}{l}85 \text { (with breakdown } \\
\text { and necrosis) }\end{array}$ & 11 & 69 & $\begin{array}{l}13 \text { (with lymphangitis } \\
\text { and phlebitis) }\end{array}$ \\
\hline Gaarenstroom et al & 2003 & 101 & Separate & No & 17 & 39 & 40 & 28 & - \\
\hline van der Zee et al & 2008 & $\begin{array}{l}47 \text { (short term) } \\
119 \text { (long term) }\end{array}$ & Separate & Yes & 34 & 21.3 & - & 25.2 & 16.2 \\
\hline
\end{tabular}

Abbreviations: $\mathrm{SCC}=$ squamous cell carcinoma; $\mathrm{SLN}=$ sentinel lymph node; $N=$ number of patients; short term = wound breakdown and infection and lymphocele; long term =lymphoedema and cellulitis/erysipelas; $-=$ not studied.

should focus on development of tailor-made postoperative therapy such as appropriate postoperative drain management and possibly lymph drainage therapy for the individual patient who still needs the inguinofemoral lymphadenectomy to survive vulvar SCC.

In conclusion, age, diabetes, 'en bloc' surgery and higher drain production on the last day the drain was in situ are risk factors for the development of short- and long-term complications. The postoperative drain management is the only factor that urges us to further studies to find the optimal postoperative protocol. Considering the rarity of SCC of the vulva, this study should

\section{REFERENCES}

Ansink AC, Sie-Go DM, van der Velden J, Sijmons EA, de Barros Lopes A, Monaghan JM, Kenter GG, Murdoch JB, ten Kate FJ, Heintz AP (1999) Identification of sentinel lymph nodes in vulvar carcinoma patients with the aid of a patent blue V injection: a multicenter study. Cancer 86(4): $652-656$

Baas PC, Schraffordt Koops H, Hoekstra HJ, van Bruggen JJ, van der Weele LT, Oldhoff J (1992) Groin dissection in the treatment of lower-extremity melanoma. Short-term and long-term morbidity. Arch Surg 127(3): 281 - 286

Barwell J, Campbell L, Watkins RM, Teasdale C (1997) How long should suction drains stay in after breast surgery with axillary dissection? Ann $R$ Coll Surg Engl 79(6): 435-437

Beitsch P, Balch C (1992) Operative morbidity and risk factor assessment in melanoma patients undergoing inguinal lymph node dissection. Am J Surg 164(5): 462-465; discussion 465-466 preferably be a randomised multicentre study in patients who undergo standardised bilateral inguinofemoral lymphadenectomy. Two different policies with respect to postoperative management may be studied in both groins of the same patient to exclude bias by patient-related factors.

\section{Conflict of interest}

The authors declare no conflict of interest.

Bell JG, Lea JS, Reid GC (2000) Complete groin lymphadenectomy with preservation of the fascia lata in the treatment of vulvar carcinoma. Gynecol Oncol 77(2): 314-318

Bundred N, Maguire P, Reynolds J, Grimshaw J, Morris J, Thomson L, Barr L, Baildam A (1998) Randomised controlled trial of effects of early discharge after surgery for breast cancer. BMJ 317(7168): $1275-1279$

Burger MP, Hollema H, Emanuels AG, Krans M, Pras E, Bouma J (1995) The importance of the groin node status for the survival of T1 and T2 vulval carcinoma patients. Gynecol Oncol 57(3): 327-334

Burke TW, Levenback C, Coleman RL, Morris M, Silva EG, Gershenson DM (1995) Surgical therapy of T1 and T2 vulvar carcinoma: further experience with radical wide excision and selective inguinal lymphadenectomy. Gynecol Oncol 57(2): 215-220 
Butler JS, Milliken DA, Dina R, Eccles SA, Maghami SG, Jameson C, Mason P, Shepherd JH, Soutter WP, Barton DP (2010) Isolated groin recurrence in vulval squamous cell cancer (VSCC). The importance of node count. Eur J Gynaecol Oncol 31(5): 510-513

Carlson JW, Kauderer J, Walker JL, Gold MA, O'Malley D, Tuller E, ClarkePearson DL (2008) A randomized phase III trial of VH fibrin sealant to reduce lymphedema after inguinal lymph node dissection: a Gynecologic Oncology Group study. Gynecol Oncol 110(1): 76-82

Chen S, Anderson MV, Cheng WK, Wongworawat MD (2009) Diabetes associated with increased surgical site infections in spinal arthrodesis. Clin Orthop Relat Res 467(7): 1670-1673

Chintamani C, Singhal V, Singh J, Bansal A, Saxena S (2005) Half versus full vacuum suction drainage after modified radical mastectomy for breast cancer- a prospective randomized clinical trial[ISRCTN24484328]. BMC Cancer 5: 11

Cormio G, Loizzi V, Gissi F, Serrati G, Panzarino M, Carriero C, Selvaggi L (2009) Cisplatin and vinorelbine chemotherapy in recurrent vulvar carcinoma. Oncology 77(5): 281-284

Courtney-Brooks M, Sukumvanich P, Beriwal S, Zorn KK, Richard SD, Krivak TC (2010) Does the number of nodes removed impact survival in vulvar cancer patients with node-negative disease? Gynecol Oncol 117(2): $308-311$

Dalberg K, Johansson H, Signomklao T, Rutqvist LE, Bergkvist L, Frisell J, Liljegren G, Ambre T, Sandelin K (2004) A randomised study of axillary drainage and pectoral fascia preservation after mastectomy for breast cancer. Eur J Surg Oncol 30(6): 602-609

De Cicco C, Sideri M, Bartolomei M, Grana C, Cremonesi M, Fiorenza M, Maggioni A, Bocciolone L, Mangioni C, Colombo N, Paganelli G (2000) Sentinel node biopsy in early vulvar cancer. Br J Cancer 82(2): 295-299

de Hullu JA, Hollema H, Lolkema S, Boezen M, Boonstra H, Burger MP, Aalders JG, Mourits MJ, van der Zee AG (2002) Vulvar carcinoma. The price of less radical surgery. Cancer 95(11): 2331-2338

de Hullu JA, Hollema H, Piers DA, Verheijen RH, van Diest PJ, Mourits MJ, Aalders JG, van der Zee AG (2000) Sentinel lymph node procedure is highly accurate in squamous cell carcinoma of the vulva. J Clin Oncol 18(15): $2811-2816$

de Hullu JA, Oonk MH, van der Zee AG (2004) Modern management of vulvar cancer. Curr Opin Obstet Gynecol 16(1): 65-72

de Vries M, Vonkeman WG, van Ginkel RJ, Hoekstra HJ (2006) Morbidity after inguinal sentinel lymph node biopsy and completion lymph node dissection in patients with cutaneous melanoma. Eur J Surg Oncol 32(7): $785-789$

Gaarenstroom KN, Kenter GG, Trimbos JB, Agous I, Amant F, Peters AA, Vergote I (2003) Postoperative complications after vulvectomy and inguinofemoral lymphadenectomy using separate groin incisions. Int $J$ Gynecol Cancer 13(4): 522-527

Gould N, Kamelle S, Tillmanns T, Scribner D, Gold M, Walker J, Mannel R (2001) Predictors of complications after inguinal lymphadenectomy. Gynecol Oncol 82(2): 329-332

Gupta R, Pate K, Varshney S, Goddard J, Royle GT (2001) A comparison of 5-day and 8-day drainage following mastectomy and axillary clearance. Eur J Surg Oncol 27(1): 26-30

Hacker NF (2005) Vulvar cancer. In Practical Gynecologic Oncology, Berek S, Hacker NF (eds) pp 543-583. Lippincott Williams \& Wilkins: Philadelphia

Hacker NF, Leuchter RS, Berek JS, Castaldo TW, Lagasse LD (1981) Radical vulvectomy and bilateral inguinal lymphadenectomy through separate groin incisions. Obstet Gynecol 58(5): 574-579

Hyde SE, Valmadre S, Hacker NF, Schilthuis MS, Grant PT, van der Velden J (2007) Squamous cell carcinoma of the vulva with bulky positive groin nodes-nodal debulking versus full groin dissection prior to radiation therapy. Int J Gynecol Cancer 17(1): 154-158

Inwang R, Hamed H, Chaudary MA, Fentiman IS (1991) A controlled trial of short-term versus standard axillary drainage after axillary clearance and iridium implant treatment of early breast cancer. Ann R Coll Surg Engl 73(5): $326-328$

Judson PL, Jonson AL, Paley PJ, Bliss RL, Murray KP, Downs Jr LS, Boente MP, Argenta PA, Carson LF (2004) A prospective, randomized study analyzing sartorius transposition following inguinal-femoral lymphadenectomy. Gynecol Oncol 95(1): 226-230

Karakousis CP, Driscoll DL (1994) Groin dissection in malignant melanoma. Br J Surg 81(12): 1771 - 1774

Katz A, Eifel PJ, Jhingran A, Levenback CF (2003) The role of radiation therapy in preventing regional recurrences of invasive squamous cell carcinoma of the vulva. Int J Radiat Oncol Biol Phys 57(2): 409-418
Kopelman D, Klemm O, Bahous H, Klein R, Krausz M, Hashmonai M (1999) Postoperative suction drainage of the axilla: for how long? Prospective randomised trial. Eur J Surg 165(2): 117-120; discussion $121-122$

Lawton G, Rasque H, Ariyan S (2002) Preservation of muscle fascia to decrease lymphedema after complete axillary and ilioinguinofemoral lymphadenectomy for melanoma. J Am Coll Surg 195(3): 339-351

Levenback C, Coleman RL, Burke TW, Bodurka-Bevers D, Wolf JK, Gershenson DM (2001) Intraoperative lymphatic mapping and sentinel node identification with blue dye in patients with vulvar cancer. Gynecol Oncol 83(2): $276-281$

Levenback C, Morris M, Burke TW, Gershenson DM, Wolf JK, Wharton JT (1996) Groin dissection practices among gynecologic oncologists treating early vulvar cancer. Gynecol Oncol 62(1): 73-77

Lin JY, DuBeshter B, Angel C, Dvoretsky PM (1992) Morbidity and recurrence with modifications of radical vulvectomy and groin dissection. Gynecol Oncol 47(1): 80-86

Manavi M, Berger A, Kucera E, Vavra N, Kucera H (1997) Does T1, N0-1 vulvar cancer treated by vulvectomy but not lymphadenectomy need inguinofemoral radiation? Int J Radiat Oncol Biol Phys 38(4): 749-753

McConnell YJ, Johnson PM, Porter GA (2009) Surgical site infections following colorectal surgery in patients with diabetes: association with postoperative hyperglycemia. J Gastrointest Surg 13(3): 508-515

Moore RG, DePasquale SE, Steinhoff MM, Gajewski W, Steller M, Noto R, Falkenberry S (2003) Sentinel node identification and the ability to detect metastatic tumor to inguinal lymph nodes in squamous cell cancer of the vulva. Gynecol Oncol 89(3): 475-479

O’Hea BJ, Ho MN, Petrek JA (1999) External compression dressing versus standard dressing after axillary lymphadenectomy. Am J Surg 177(6): $450-453$

Ogihara H, Takeuchi K, Majima Y (2009) Risk factors of postoperative infection in head and neck surgery. Auris Nasus Larynx 36(4): 457-460

Oonk MH, Hollema H, de Hullu JA, van der Zee AG (2006) Prediction of lymph node metastases in vulvar cancer: a review. Int J Gynecol Cancer 16(3): $963-971$

Perez CA, Grigsby PW, Chao C, Galakatos A, Garipagaoglu M, Mutch D, Lockett MA (1998) Irradiation in carcinoma of the vulva: factors affecting outcome. Int J Radiat Oncol Biol Phys 42(2): 335-344

Podratz KC, Symmonds RE, Taylor WF, Williams TJ (1983) Carcinoma of the vulva: analysis of treatment and survival. Obstet Gynecol 61(1): $63-74$

Rouzier R, Haddad B, Dubernard G, Dubois P, Paniel BJ (2003) Inguinofemoral dissection for carcinoma of the vulva: effect of modifications of extent and technique on morbidity and survival. $\mathrm{J} \mathrm{Am}$ Coll Surg 196(3): 442-450

Serpell JW, Carne PW, Bailey M (2003) Radical lymph node dissection for melanoma. ANZ J Surg 73(5): 294-299

Sliutz G, Reinthaller A, Lantzsch T, Mende T, Sinzinger H, Kainz C, Koelbl $\mathrm{H}$ (2002) Lymphatic mapping of sentinel nodes in early vulvar cancer. Gynecol Oncol 84(3): 449-452

Soon PS, Clark J, Magarey CJ (2005) Seroma formation after axillary lymphadenectomy with and without the use of drains. Breast 14(2): $103-107$

Stehman FB, Ali S, DiSaia PJ (2009) Node count and groin recurrence in early vulvar cancer: a Gynecologic Oncology Group study. Gynecol Oncol 113(1): $52-56$

Stehman FB, Bundy BN, Dvoretsky PM, Creasman WT (1992a) Early stage I carcinoma of the vulva treated with ipsilateral superficial inguinal lymphadenectomy and modified radical hemivulvectomy: a prospective study of the Gynecologic Oncology Group. Obstet Gynecol 79(4): $490-497$

Stehman FB, Bundy BN, Thomas G, Varia M, Okagaki T, Roberts J, Bell J, Heller PB (1992b) Groin dissection versus groin radiation in carcinoma of the vulva: a Gynecologic Oncology Group study. Int J Radiat Oncol Biol Phys 24(2): 389-396

Tadych K, Donegan WL (1987) Postmastectomy seromas and wound drainage. Surg Gynecol Obstet 165(6): $483-487$

Talbot ML, Magarey CJ (2002) Reduced use of drains following axillary lymphadenectomy for breast cancer. ANZ J Surg 72(7): 488-490

Trussell J, Gerkin R, Coates B, Brandenberger J, Tibi P, Keuth J, Montefour K, Salisbury H, Ferrara J (2008) Impact of a patient care pathway protocol on surgical site infection rates in cardiothoracic surgery patients. Am J Surg 196(6): $883-889$; discussion 889

van de Nieuwenhof HP, Massuger LF, van dAI, Bekkers RL, Casparie M, Abma W, van Kempen LC, de Hullu JA (2009) Vulvar squamous cell 
carcinoma development after diagnosis of VIN increases with age. Eur J Cancer 45(5): $851-856$

van der Zee AG, Oonk MH, de Hullu JA, Ansink AC, Vergote I, Verheijen RH, Maggioni A, Gaarenstroom KN, Baldwin PJ, Van Dorst EB, van dV, Hermans RH, van der PH, Drouin P, Schneider A, Sluiter WJ (2008) Sentinel node dissection is safe in the treatment of early-stage vulvar cancer. J Clin Oncol 26(6): 884-889

van Doorn HC, Ansink A, Verhaar-Langereis M, Stalpers L (2006) Neoadjuvant chemoradiation for advanced primary vulvar cancer. Cochrane Database Syst Rev 3: CD003752

van Heurn LW, Brink PR (1995) Prospective randomized trial of high versus low vacuum drainage after axillary lymphadenectomy. Br J Surg 82(7): $931-932$

Wagenaar HC, Colombo N, Vergote I, Hoctin-Boes G, Zanetta G, Pecorelli S, Lacave AJ, van Hoesel Q, Cervantes A, Bolis G, Namer M, Lhomme C, Guastalla JP, Nooij MA, Poveda A, Scotto di Palumbo V, Vermorken JB (2001) Bleomycin, methotrexate, and CCNU in locally advanced or recurrent, inoperable, squamous-cell carcinoma of the vulva: an EORTC Gynaecological Cancer Cooperative Group Study. European Organization for Research and Treatment of Cancer. Gynecol Oncol 81(3): $348-354$
Witteveen PO, van der Velden J, Vergote I, Guerra C, Scarabeli C, Coens C, Demonty G, Reed N (2009) Phase II study on paclitaxel in patients with recurrent, metastatic or locally advanced vulvar cancer not amenable to surgery or radiotherapy: a study of the EORTC-GCG (European Organisation for Research and Treatment of Cancer-Gynaecological Cancer Group). Ann Oncol 20(9): 1511-1516

Woelber L, Kock L, Gieseking F, Petersen C, Trillsch F, Choschzick M, Jaenicke F, Mahner S (2011) Clinical management of primary vulvar cancer. Eur J Cancer 47(15): 2315-2321

Woodworth PA, McBoyle MF, Helmer SD, Beamer RL (2000) Seroma formation after breast cancer surgery: incidence and predicting factors. Am Surg 66(5): $444-450$; discussion 450-451

Yii M, Murphy C, Orr N (1995) Early removal of drains and discharge of breast cancer surgery patients: a controlled prospective clinical trial. Ann $R$ Coll Surg Engl 77(5): 377-379

Zavotsky J, Jones RC, Brennan MB, Giuliano AE (1998) Evaluation of axillary lymphadenectomy without axillary drainage for patients undergoing breast-conserving therapy. Ann Surg Oncol 5(3): 227-231

Zhang SH, Sood AK, Sorosky JI, Anderson B, Buller RE (2000) Preservation of the saphenous vein during inguinal lymphadenectomy decreases morbidity in patients with carcinoma of the vulva. Cancer 89(7): 1520-1525

This work is published under the standard license to publish agreement. After 12 months the work will become freely available and the license terms will switch to a Creative Commons Attribution-NonCommercial-Share Alike 3.0 Unported License. 